Kardiologe 2013 - 7:216-216

DOI 10.1007/s12181-013-0493-4

Online publiziert: 22. Mai 2013

(c) Springer-Verlag Berlin Heidelberg 2013

\section{F.-P. Pfabe}

Klinik für Gefäßmedizin, Asklepios Klinikum Uckermark GmbH, Schwedt

\section{Erratum zu: Akutes Koronarsyndrom bei koronarem Gigantismus}

\author{
Kardiologe 6:517-524 \\ http://dx.doi.org/10.1007/s12181-012-0442-7
}

Im oben genannten Beitrag wurde auf Seite 521 im Abschnitt „Klinik, Letalität und Komplikationen“ die Abkürzung APS falsch aufgelöst.

Richtig ist:

APS $=$ Angina-pectoris-Symptomatik

Wir bitten um Beachtung

Die Redaktion

\section{Korrespondenzadresse}

\section{Dr. F.-P. Pfabe}

Klinik für Gefäßmedizin, Asklepios Klinikum Uckermark $\mathrm{GmbH}$

Auguststr. 23 Schwedt f.pfabe@asklepios.com
26. bis 27. September 2013

\section{Deutscher Internistentag}

Informieren Sie sich über wichtige berufspolitische Themen mit Bezug zur Inneren Medizin, und nutzen Sie gleichzeitig die breiten Möglichkeiten zur internistischen Fortbildung auf hohem

klinisch-wissenschaftlichen Niveau.
Langenbeck-Virchow-Haus, Berlin

Der Berufsverband Deutscher Internisten e. V. lädt Sie herzlich zum 6. Deutschen Internistentag nach Berlin ein.

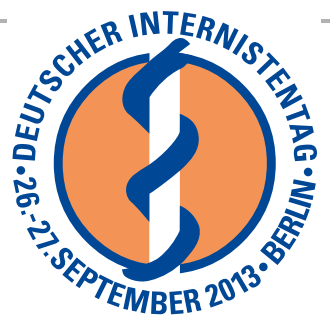

Fortbildung: Kardiologie $\quad$ Neues zu Diagnostik und Behandlung

Donnerstag 26.09.2013 Hörsaal 17.00-18.30 Uhr

Vorsitz Prof.Dr.med. H.M. Hoffmeister, Solingen Dr. med. N. Smetak, Kirchheim

(2) Neue Echobildgebung

PD. Dr. med. W. Fehske, Köln

¿ Interventionelle kardiologische Klappenbehandlung Prof.Dr. med. H. Darius, Berlin

(2) Hochdruckablation - Renale Denervation Dr. med. Andrea Behne, Berlin

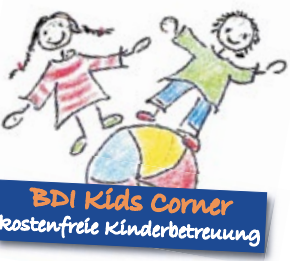

